\title{
Kontrastive Phraseologie deutsch-tschechisch am Beispiel der Komponente sArsch،
}

>Gesäß $\curlywedge^{1}$ ist der standardsprachliche Ausdruck für das Körperteil, auf dem man sitzt, veraltet Steiß genannt. In der Kindersprache sagt man Po, Popo und auch Podex, daneben pflegt man in den Familien noch die eine oder andere Benennung (Pöker, Pöks in Norddeutschland) zu verwenden. Umgangssprachlich heißt es Hinterer, Hintern, Hinterpartie, Hinterseite, Hinterster, Hinterteil und Hinterviertel. Als Euphemismus kennen wir die vier Buchstaben, der Allerwerteste, die Kehrseite und der verlängerte Rücken. Scherzhaft kann man das Gesäß auch Kehrseite, Gegenteil, Hintergestell, Sitzfläche und Sitzfleisch nennen. Eine saloppe Bezeichnung ist dann Hinterkastell oder Kiste. Landschaftlich sind die Ausdrücke wie Pöter, Tokus, Hintersteven (scherzhaft) oder Dups (bes. schlesisch) verbreitet. Die Medizin und Anatomie haben ihre Begriffe und wer es derb liebt, sich deftig auszudrücken pflegt und das Vulgäre nicht scheut, redet - seltener schreibt - Arsch.
Die vorliegende

Untersuchung und das dafür erstellte Korpus zeigen, dass Deutsch und Tschechisch auf dem Gebiet des Vergleichs der Phraseologismen mit der Komponente ,Arsch zu $29 \%$ formale und inhaltliche Gemeinsamkeiten aufweisen. Dies geht aus den Prozentzahlen der vollständigen (14\%) und der partiellen (15\%) Äquivalenz hervor. Nur inhaltliche Gemeinsamkeiten werden mit der rein semantischen Äquivalenz (39\%) repräsentiert. Dies ist zugleich die größte Gruppe des Vergleichs. Als Verschiedenheiten in den beiden Sprachen gelten die Gruppen der Nulläquivalenz (27\%) und der phraseologischen faux amis` (5\%). Insgesamt sind dies also $32 \%$. 
In der Phraseologie sind Körperteile sehr produktive Elemente und das gilt noch umso mehr, wenn es sich um so einen alle Aufmerksamkeit auf sich ziehendes Körperteil wie das Gesäß handelt. Gesäß wäre jedoch langweilig, man bevorzugt dann schon lieber Arsch. Stilistisch bewegt man sich dabei vor allem auf der saloppen, derben, vulgären Sprachebene, inhaltlich geht es oft um Herabwürdigung, Beleidigung, Geringschätzung und Beschimpfung, mitunter auch um Sexismus. Die Kontexte sind vorwiegend die Umgangssprache, aber - wie man dem folgenden Beitrag entnehmen kann - findet dieser Ausdruck seinen Weg auch in die geschriebene Sprache.

\section{Ziele und Methodologie der Untersuchung}

Das Ziel der Untersuchung besteht darin, festzustellen, wie hoch der Grad der Übereinstimmung zwischen den Phraseologismen im Deutschen mit der Komponente >Arsch u und den Entsprechungen im Tschechischen ist. Anhand der gedruckten und der elektronischen phraseologischen Wörterbücher, die im Literaturverzeichnis aufgeführt sind, wird ein Korpus zusammengestellt. Den Phraseolexemen im Deutschen werden ihre Pendants im Tschechischen zugeordnet und anschließend mit Hilfe der Klassifikation von Henschel (1993) in vier Gruppen eingeteilt. Die vollständige, die partielle und die rein semantische Äquivalenz stellen die Typen der phraseologischen Äquivalenz dar, d.h. der Phraseologismus im Deutschen hat eine phraseologische Entsprechung im Tschechischen. Die Nulläquivalenz stellt die nichtphraseologische Äquivalenz dar, was bedeutet, dass es im Tschechischen schon eine Entsprechung gibt, aber sie ist nicht phraseologisch. Darüber hinaus erwähnt Henschel noch die phraseologischen falschen Freunde.

Die Verwendung und die Aspekte der Bedeutung der lexikographisch fixierten phraseologischen Wortverbindungen werden für Deutsch in dem Deutschen Referenzkorpus (DeReKo-2017-I) (zit. als DeReKo) vom Institut für Deutsche Sprache in Mannheim und für Tschechisch in dem Tschechischen Nationalkorpus SYN 2015 (zit. als TscheKo) überprüft.

\section{Die Begriffe `Phraseologismus` und `Äquivalenz`}

Unter dem Begriff >Phraseologimus` verstehen wir im Hinblick auf die einschlägige Fachliteratur ${ }^{2}$ eine Einheit von mindestens zwei Wörtern 
(Polylexikalität), die relativ stabil (Stabilität, relative Festigkeit) und mehr oder weniger idiomatisch (Idiomatizität) ist. Wir unterscheiden die idiomatischen, teilidiomatischen und die nichtidiomatischen festen Wendungen. Weitere Merkmale der Phraseologismen sind die Lexikalisierung, d.h. der Eintrag im Lexikon ähnlich wie bei anderen Lexemen, und die Reproduzierbarkeit, d.h. dass die Phraseolexeme beim Verwenden in der Sprache nicht neu gebildet, sondern als fertige Einheiten reproduziert werden. Als Synonyme zum Begriff Phraseologismus verwenden wir die Termini Phrasem, Phraseolexem, phraseologische Wortverbindung und Wortgruppenlexem.

Für die vorliegende Untersuchung verwenden wir den Terminus der Äquivalenz so, wie sie von Henschel verstanden wird, wonach unter diesem Begriff »die kommunikative Entsprechung zwischen Ausgangs- und Zielsprache einer Einheit $\aleph^{3}$ ist, wobei »aufgrund der Unterschiede in den semantischen und grammatischen Merkmalen [...] immer nur eine Annäherung an die vollständige Äquivalenz möglich [ist] «. ${ }^{4}$ Sie weist im Weiteren darauf hin, dass »selbst das Vorhandensein eines lexikographisch fixierten Äquivalents [...] im Kontext nicht die beste kommunikative Entsprechung sein [muss] $\ll^{5}$

\section{Typen der phraseologischen Äquivalenz}

\subsection{Vollständige Äquivalenz}

Unter vollständig äquivalenten Phraseologismen versteht $\mathrm{Henschel}^{6} \mathrm{Phra}-$ sempaare, die semantisch, strukturell und lexikalisch übereinstimmen, wobei sie auch das gleiche Bild haben. In unserem Korpus wurden 16 solche Phrasempaare gefunden. Im Weiteren wollen wir uns mit vier interessanten Beispielen näher befassen.

Ein derbes, vollständig äquivalentes Paar ist >jmdm. in den Arsch kriechen ` in der Bedeutung: >in würdeloser Form jmdm. schmeicheln, sich un-

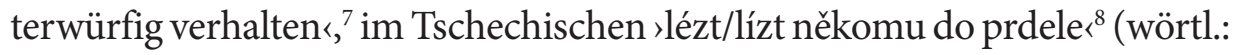
jmdm. in den Arsch kriechen) im gleichen Sinne. Im DeReKo wurden zum

3 Henschel: Die Phraseologie der tschechischen Sprache, S. 137.

4 Ebd.

5 Ebd.

6 Ebd., S. 138.

7 Duden 11 (2002), S. 62.

8 Heřman et al.: Deutsch-tschechisches Wörterbuch (S. 108) geben auch noch die Varianten an: lézt/lízt někomu do zadku/někam (wörtl.: jmdm. in den Hintern/irgendwohin kriechen). 
14.10.2017 insgesamt 57 Belege zu der Nennform des Phraseologismus gefunden. In vielen Fällen werden Personen mit dieser deftigen Wendung zitiert, gelegentlich wird sie allerdings auch von Journalisten in ihren Texten verwendet und zwar ganz ohne Anführungszeichen, also ganz bewusst und ohne Distanzierung. Im TscheKo wurde zum 26.10.2017 ein Beleg zu der Nennform im Tschechischen gefunden.

Ich bin immer noch weit unten auf der Liste derjenigen, die die tollen Rollen bekommen. Man ist von so vielen Dingen abhängig. Muss irgendwelchen 25-jährigen WunderkindRegisseuren oder Studiomanagern in den Arsch kriechen. ${ }^{9}$ Und manchmal sagst du dir: »Scheiß drauf!« (FOC00/ OKT.00104 FOCUS, 09.10.2000, S. 278-280, Sachgebiet: Unterhaltung, Originalressort: ENTE/Entertainment; 14 Stunden in Latex)

Předloží ted' - on, který zjevně stojí nalevo a navíc je kupodivu sociální demokrat sociálnědemokratickou bílou knihu, v které onen skandál bude omlouvat, bude zahlazovat vinu a lézt do prdele komunistickým katanům? (Enquist, Per Olov (2011): Jiný život. Překlad: Černík, Zbyněk. Brno: Host.)

Das nächste Beispiel, das zu der vollständigen Äquivalenz gehört, ist das derbe Phraseolexem `am Arsch der Welt $<,{ }^{10} \mathrm{im}$ Tschechischen $>$ v prdeli světa (wörtl.: im Arsch der Welt) in dem Sinne von `an einem [...] sehr abgelegenen Ort ${ }^{11}$ Das DeReKo bringt zum 20.10.2017 insgesamt 336 Belege zu der Anfrage »am Arsch der Welt«. Eine ganze Reihe der Belege beziehen sich auf ein Boulevard-Theaterstück mit diesem Titel, der reißerisch klingt. Ab und zu findet man diesen Phraseologismus auch selbstironisch verwendet, beispielsweise wenn eine Wanderweg-Beschilderung dorthin, nämlich an den Arsch der Welt, führt. Schließlich verwenden Journalisten diesen Begriff mitunter mit Anführungszeichen, um sich von dem Vulgären mittels des Zitierens zu distanzieren.

Vor meinem Jahr dachte ich, dass ich am Arsch der Welt lebe, von allen abgeschnitten. Dass die Natur hier viel schöner als anderswo ist, habe ich erst in Frankreich so richtig gemerkt. Da gab es keine Seen und keinen Wald. Über das Haus meiner Familie flogen ständig Flugzeuge, da setzte man sich kaum vor die Tür. (NKU04/JUN.04378 Nordkurier, 17.06.2004, Sachgebiet: Lokales, Originalressort: Lokales Mecklenburg-Strelitz; »Meine Heimat ist die weite Welt«)

Im TscheKo wurden zum 20.10.2017 insgesamt 6 Treffer zu diesem Phraseologismus gefunden.

Ty vole, já celej tejden dvakrát za den musím přežít na tý jejich opičí dráze a ještě by po mně chtěli nějaký lístky. Kundy vylízaný. Ted' jsem vylezl z šaliny někde v prdeli světa. Tady budu stát půl hodiny v tý kose, než pojede další šalina. Kůůůůrva. Vystoupil jsem

9 Die Hervorhebung durch Fettschrift in allen Belegen stammt von mir (J. H.).

10 Duden 11 (2002), S. 61 gibt auch die Variante san den Arsch der Welt $\triangleleft$ an.

11 Ebd. 
na Masné. Tady je, vole, bazar s kárama. Tak jsem vlezl do bazaru to jenom vokouknout. (Šimáček, Jiřri (2012): Charakter. Brno: Host.)

Der umgangssprachliche, saloppe bis derbe Phraseolexem im Deutschen 'wie der Arsch auf den Eimer passen in der Bedeutung von >genau/ausgezeichnet passen; gelegen kommen; sich eignen $\iota^{12}$ hat seine Entsprechung im tschechischen `sednout k něčemu jako prdel na hrnec (wörtl.: wie der Arsch auf den Topf zu etw. passen). Das Bild kommt wohl von der Situation, wo ein Hintern bestens auf einen Nachttopf passt. ${ }^{13}$ Diese Zuordnung erfolgt unter der Prämisse, ${ }^{14}$ dass auch Phraseme, in denen eine Komponente durch ein Synonym wiedergegeben wird, zur Gruppe der vollständigen Äquivalenz gehören. Das DeReKo liefert zum 14.10.2017 insgesamt 5 Treffer zu diesem Phraseologismus. Das TscheKo liefert nur 2 Treffer.

") Aber du gehörst doch hierher wie der Arsch auf den Eimer`, fällt da Hartmann seinem Ensemble-Star ins Wort." Diese Formulierung ist sehr prägnant, aber wahr. Die Österreicher haben dich in einem Ausmaß adoptiert, da stellen sich die Ohren nach den Rezeptionsgewohnheiten ein. Obwohl du doch sehr deutsch sprichst. >Wobei<, kommt Hartmann zum Wesentlichen, >Nestroy ja keinen Dialekt schreibt, sondern eine Kunstsprache`. (NEW13/JUL.00279 NEWS, 25.07.2013, S. 62, 63, 64, 65, Sachgebiet: Kultur, Originalressort: ALL Kultur; Komet über Salzburg)

Uklízela jsem a přitom poslouchala v rádiu zprávy. Máme nového ministra kultury. Ve svém úvodním proslovu řekl, že se chce za kulturu bít a taky chce naplňovat zadání pana premiéra, protože jeho projevy padnou jako prdel na hrnec! Máme prima ministra. Ano, kultury. (Boučková, Tereza (2008): Rok kohouta. Praha: Odeon.)

Ein weiterer derber Phraseologismus lautet $>$ den/einen (ganzen) Arsch voll(er) Schulden haben $<$ im Sinne von $>$ hoch verschuldet sein $<,{ }^{15}$ den man ins Tschechische ${ }^{16}$ mit `mít dluhů tři prdele` (wörtl.: drei Arsche von Schulden haben) übertragen kann. Das DeReKo liefert zum 14.10.2017 insgesamt 7 Treffer. Allerdings ist der Phraseologismus im Tschechischen verlängert und die Bedeutung intensivierend. Nach Henschel ${ }^{17}$ gehört jedoch die unterschiedliche Explizität noch zu der vollständigen Äquivalenz. Das TscheKo gibt zum 20.10.2017 nur einen Treffer an.

12 Redensartenindex, Stichwort: »wie der Arsch auf den Eimer passen«.

13 Ebd.

14 S. Henschel: Die Phraseologie der tschechischen Sprache, S. 139.

15 Heřman et al.: Deutsch-tschechisches Wörterbuch, S. 103.

16 Bei Heřman et al. (Deutsch-tschechisches Wörterbuch, S. 104) findet man noch die Varianten >být po prdel v dluzích, mít fůru/spoustu/spousty dluhů<; >být zadluženej až po uši` (wörtl.: bis zum Arsch in Schulden sein, einen Haufen / eine Menge von Schulden haben; verschuldet bis zu den Ohren sein).

17 Henschel: Die Phraseologie der tschechischen Sprache, S. 139. 
Deutschland nach der Wahl: der Innenminister beim Rock 'n' Roll; Westerwelle wäre lieber Finanzminister, weil er dann »den Arsch voller Schulden hätte«; die Linkspartei zieht mit Sprengstoffgürtel gegen die Reichen zu Felde, und unsere Kanzlerin erfreut sich der Wechseljahre, weil nun endlich die anderen bluten. (HMP05/DEZ.02191 Hamburger Morgenpost, 21.12.2005, S. 23; Penisman und der Rock'n'Roll)

»No prosím, případ vyřešen.« »Počkat, « skočím jim do toho »já neříkal, že si něčím přivydělává - je to prostě opravářr, co má doma v Nacogdoches tř̀i prdele dluhủ. Pojdte se podívat na jeho vizitku.« (Pierre, D. B. C. (2005): Vernon Bůh Little. Překlad: Petrů, David. Praha: Odeon.)

\subsection{Partielle Äquivalenz}

Als partiell äquivalent werden solche Phrasempaare definiert, die »zwar als Entsprechungen erkennbar sind, andererseits aber deutliche Unterschiede im Bild, der lexikalischen Entsprechung, der Struktur, der Semantik oder der Funktion aufweisen $\ll .{ }^{18}$ Im Weiteren spricht Henschel von Abweichungen, ${ }^{19}$ die in dieser Gruppe vorkommen können, worunter sie den Komponententausch, die funktionalen Unterschiede, die Unterschiede im Bildcharakter und die semantischen Unterschiede versteht. Unser Korpus weist 17 Phrasempaare auf, die dieser Definition entsprechen. Mit einigen wollen wir uns hier näher befassen.

Der derbe Phraseologismus >leck mich am Arsch!< im Sinne von >lass mich in Ruhe ${ }^{20}$ findet sein Pendant in dem tschechischen $>$ vyliž mi prdel! ${ }^{21}$ (wörtl.: leck mir den Arsch aus). In dem DeReKo wurden zum 14.10.2017 insgesamt 307 Treffer zu dieser Suchanfrage gefunden. Bei allen Belegstellen kommt dieser Phraseologismus als direkte Rede vor. Berühmt wurde dieser Phraseologismus als Teil einer Replik in Goethes Drama Götz von Berlichingen. Zur Aufgabe aufgefordert, ruft Götz mit voller Inbrunst: „Sag deinem Hauptmann: Vor Ihro Kayserliche Majestät habe ich, wie immer, schuldigen Respekt. Er aber, sag’s ihm, kann mich im Arsch lecken! «22 Bemerkenswert ist, dass manche Lektüretexte für Schüler die besagte Stelle nicht ausschreiben, sondern mit drei Gedankenstrichen ersetzen. ${ }^{23}$ Es kommen auch andere Formen vor, um das Tabu-Wort nicht zu schreiben oder zu sagen, wie die Euphemismen `das Götz-Zitat‘, ১Schwäbischer Grußく, die

21 Im Tschechischen gibt es in der gleichen Bedeutung, nämlich `hör auf mich zu belästigen $`$ noch die Variante >polib mi prdel! ( (wörtl.: küss mir den Arsch). 
Abkürzung >LmaA oder zahllose Varianten wie >Leck mich am Ärmel ‘. ${ }^{24}$ Goethe war jedoch nicht der einzige und nicht der erste Dichter, der diese Wendung, die eine kraftvolle Abwehr oder Zurückweisung bedeutet, verwendet. Röhrich ${ }^{25}$ erwähnt unter anderem Martin Luther, Hans Sachs und Grimmelshausen.

Auch in Polen war für den Kandidaten nicht viel zu holen - vor allem, weil sein Sprecher sich mit den mitreisenden Berichterstattern anlegte. "Leck mich am Arsch « soll er gestern einen Journalisten angeblafft haben, der den Bewerber darauf ansprechen wollte, dass Romney seit Beginn ganze drei Fragen vom Begleittross genehmigt hatte. Das Bild eines souveränen Staatsmannes sieht jedenfalls anders aus. (BRZ12/AUG.01860 Braunschweiger Zeitung, 01.08.2012; Romneys Fettnäpfchen-Tournee)

Im TscheKo wurde zum 20.10.2017 lediglich ein Beleg gefunden, ebenfalls in der direkten Rede.

Bubeník Murch po něm chtěl hodit paličky, ale pak si uvědomil, že si je nechal soustružit na zakázku, jelikož se už nevyráběly, takže jen prohlásil: „Vyliž mi prdel, frajere! « vstal a nikoli poprvé odešel. (Sterling, Bruce (ed.) (2000): Zrcadlovky. Překlad: Tschorn, Robert (et al.). Plzeň: Laser.)

Das Phraseolexem >jmdm. den Arsch polieren $\iota^{26}$ in der Bedeutung >strafen, züchtigen, schlagen hat seine partiell äquivalente Entsprechung in dem tschechischen Phrasem ‘zmalovat někomu prdel ( wörtl.: jmdm. den Arsch bemalen/anmalen) in dem gleichen Sinne. Sowohl im DeReKo als auch im TscheKo konnte zum 25.10.2017 jeweils ein Treffer gefunden werden konnten.

»Ich war bei Vietnam, Libyen, Grenada, Panama und den Falklandinseln mit von der Partie, aber ich habe etwas Derartiges noch nie erlebt «, sagt ein Geheimdienstoffizier. - »Unser Job ist es, dem Kerl, der seine ganze Nachbarschaft drangsaliert, eine empfindliche Lektion zu erteilen «, ergänzt ein junger Luftwaffen-Captain. - »Wir müssen hin und Saddam Hussein abservieren - und genau das werden wir auch tun «, sagt ein Marineleutnant. »Dies wird kein Vietnam werden. Wir werden ihm den Arsch polieren. "(Z90/AUG.00292 Die Zeit, [Wochenzeitung], 24.08.1990, S. 2. Originalressort: DIE ZEIT; James Adams: »Dies wird kein Vietnam werden «)

»Kde je Gary? «»Spí.« Hugo se zahihňal. »Pokaždé dlouho spí. Jestli ho v sobotu ráno budu budit, tak mi prý zmaluje prdel.«Kluk se rozvalil na gauči vedle Richieho. »To znamená, že mě plácne přes zadek. « Rosie zavrtěla hlavou. »Višs, že to tak nemyslí.« Hugo neodpověděl. (Tsiolkas, Christos (2011): Facka. Překlad: Kačer, Tomáš. Brno: Host.)

Das nächste, derbe, partiell äquivalente Paar ist >jmdm. am Arsch vorbeigehen $\triangleleft$ im Deutschen und `někdo/něco je někomu u prdele ( (wörtl.: jmd./etw. ist jmdm. am/beim Arsch) im Tschechischen. Beide Phraseologismen haben 
die gleiche Bedeutung, nämlich >jmdn. nicht berühren, kalt lassen $<.{ }^{27}$ In der deutschen Presse wird dieser Ausdruck häufig verwendet. Zum 25.10.2017 wurden insgesamt 385 Treffer im DeReKo gefunden. Das TscheKo bringt zum 25.10.2017 insgesamt 64 Treffer. Interessanterweise gibt es auch 4 Treffer mit dem Verb `mít` (wörtl.: haben), also `někdo má něco u prdele $\iota^{28}$ (wörtl.: jmd. hat etw. am/beim Arsch) in der gleichen Bedeutung.

FOCUS: Haben Sie noch einen Draht zu Hollywood?

Depp: Nein. Dieser ganze Zirkus dort geht mir seit Jahren am Arsch vorbei. Ich lebe mit meiner Familie die meiste Zeit sehr zurückgezogen auf einem Bauernhof in Südfrankreich. (FOC02/FEB.00550 FOCUS, 25.02.2002, S. 178-181, Sachgebiet: Unterhaltung, Originalressort: ENTE/Entertainment; Exorzist in eigener Sache)

Vadí mi naopak zjednodušující pohled na povolební náladu u nás. A to ve stylu zhrzení fandové knížete versus vítězní Zemanovi vidláci. Mně je například úplně u prdele, že kníže nevyhrál, ale podepsal jsem, že Zeman není můj prezident, a to ve smyslu prezidenta jako někoho, koho bych měl mít chut' následovat nebo se $\mathrm{k}$ němu vztahoval jako $\mathrm{k}$ autoritě protože autoritou není. (Reflex, č. 7/2013)

Der derbe Phraseologismus >seinen Arsch verwetten (können)< findet seine Entsprechung in dem tschechischen Phraseolexem >vsadit boty< in der Bedeutung >sich einer Sache ganz sicher sein $\prec .{ }^{29}$ Das DeReKo liefert zu dieser Anfrage zum 20.10.2017 insgesamt 11 Treffer, das TscheKo lediglich 8 Belege. Sowohl im Deutschen als auch im Tschechischen kann der Satz mit der Konjunktion `dass` fortgesetzt werden. Es ist auch möglich, das Verweiselement $>$ darauf $\prec$ zu verwenden.

Ja, weil er sagte: »Das schadet der Firma.»

Also war das Geld schuld.

Irgendwie ja. Ich möchte meinen Arsch verwetten, dass Udo bis heute noch keinen Satz aus dem Buch gelesen hat. Die Leute haben ihm erzählt, da stünden schlimme Dinge drin, und er stand dann auf einmal vor mir (Kante macht Lindenbergs Stimme nach): Ey, pass mal auf. Du schreibst jetzt, dass du Schutzgeld kassiert hast, Leute verdroschen hast. «Ich sag’ »Udo, das ist 40 Jahre her.« (U16/JUN.02559 Süddeutsche Zeitung, 17.06.2016, S. 22. - Sachgebiet: Wirtschaft, Originalressort: Wirtschaft; JAN SCHMIDBAUER, ANGELIKA SLAVIK: »Jetzt habe ich auf einmal Existenzängste«)

Er sagt: »Würde ich Waterboarding erlauben? Darauf können Sie Ihren Arsch verwetten. Jederzeit. Ich würde sogar noch mehr erlauben. Es funktioniert. Und wenn es nicht funktioniert, haben sie es doch verdient.« (T16/MAR.00431 die tageszeitung, 04.03.2016, S. 13. Originalressort: tazzwei; Arno Frank: Es war einmal in Washington)

Krev mi tuhla v žilách i z roztřesených amatérských klipů: tsunami, která bourá město jak domeček z karet, anebo záběry z jedoucího auta, které se marně snaží uniknout padající hradbě vody. Nic z toho v katastrofických filmech zatím nebylo. Proto vsadím boty, že

28 Mehr dazu weiter unten, Kapitel 5 (»Phraseologische >faux amis «).

29 Redensartenindex, Stichwort: »seinen Arsch verwetten (können)«. 
všechny tyhle sekvence se už určitě dostaly do obrazových bank hollywoodských specialistů na počítačové efekty. Př́rodní anebo jiná katastrofa prostě dokáže namíchat karty tak, jak by to žádný scenárista nevymyslel. (Instinkt, č. 8/2011)

\subsection{Rein semantische Äquivalenz}

Die rein semantische Äquivalenz umfasst »Phraseme, die keinerlei Übereinstimmung des Komponentenbestandes sowie des Bildes aufweisen und deren strukturelle und funktionale Parallelität eher zufälligen Charakter trägt « ${ }^{30}$ Henschel fügt hinzu, dass diese phraseologischen Paare »die annähernd gleiche Bedeutung « ${ }^{31}$ aufweisen. Die der Gruppe der rein semantischen Äquivalenz zuzurechnenden Phraseolexeme sind in unserem Korpus recht zahlreich vertreten, es handelt sich um 43 phraseologische Paare. Drei interessante Beispiele werden hier besprochen.

Das erste derbe Beispiel, das im Korpus zu der rein semantischen Äquivalenz gefunden wurde, ist `den Arsch zukneifen «, im Tschechischen ${ }^{32}$ >prdět do hlíny ${ }^{33}$ (wörtl.: in den Ton furzen) in der Bedeutung >sterben ${ }^{34}{ }^{34}$ Das Bild, das dem deutschen Phraseologismus zugrunde liegt, verweist auf die Starrheit des gestorbenen Körpers, während im Tschechischen die Leiche schon als unter der Erde liegend betrachtet wird. Im DeReKo wurde zum 20.10.2017 lediglich ein Beleg für die Anfrage der Nennform gefunden. Wir belassen den deutschen Beleg absichtlich in der ausführlichen Form. Das TscheKo liefert zum gleichen Datum vier Treffer, allerdings alle aus einer Publikation.

Die Dudenredaktion wagte sich in die Abgründe der deutschen Alltagssprache von Franziska Wolffheim

»Der hat doch den Arsch offen« - so machte 1985 eine junge Christin ihrem Unmut über den damaligen Verteidigungsminister Apel Luft. »Ich hätte mir vor Wut in den Arsch beißen können - fünf Richtige, und den Lottoschein nicht abgegeben! « So stand's einst im Spiegel. »Eines Tages müssen wir alle den Arsch zukneifen. «So benutzte Erich Maria Remarque das harte Wort. Das Five-Letter-Word der deutschen Sprache gilt in manchen Kreisen noch immer als Unwort. Daß es kein einfallsloser Kraftausdruck ist, sondern fröhlich durch eine Vielzahl von Redewendungen geistert und stets neue Verbindungen

Henschel: Die Phraseologie der tschechischen Sprache, S. 142.

31 Ebd.

32 Es gibt nach Heřman et al. (Deutsch-tschechisches Wörterbuch, S. 106) weitere Varianten im Tschechischen zu diesem Phrasem im gleichen Sinne, nämlich `sterben` und zwar `natáhnout bačkory, brka‘; >zaklepat bačkorama; zkápnout; zhebnout` (wörtl.: die Hausschuhe / die Federn anziehen; mit den Hausschuhen klopfen; abkratzen; verrecken).

33 In Heřman et al. (Deutsch-tschechisches Wörterbuch, S. 106) ist die Komponente >jít` (wörtl.: gehen) fakultativ, nämlich >(jít) prdět do hlíny` (wörtl.: in den Ton furzen (gehen)).

34 Duden 11 (2002), S. 61. 
eingeht, haben wir jetzt schriftlich: nicht aus Schülerzeitungen oder Schimpfwörterheftchen, sondern von höchster Instanz - der Duden-Redaktion mit Sitz in Mannheim. Sie hat an die fünfzig Belege für den kreativen sprachlichen Umgang mit dem menschlichen Hinterteil gesammelt. Dieser neue Duden, der Band mit der Nummer 11, wirkt neben seinen eher akademischen Vorgängern wie ein Enfant terrible. Zum erstenmal überhaupt hat sich die Redaktion ausschließlich die deutsche Alltagssprache vorgeknöpft. (NUN93/ JUL.01255 Nürnberger Nachrichten, 17.07.1993, S. 2; Aufs Maul geschaut - Die Dudenredaktion wagte sich in die Abgründe der deutschen Alltagssprache)

Vážně už nikomu tu moji knížku nevnutíš? To jsi vážně takovej ničema a duševní lenoch s mizerným kritickým úsudkem? Pak si mě fakt nezasloužíš. Běž si klidně prdět do hlíny. Jo, ty. $\mathrm{V}$ tu dobu už budu sám do hlíny prdět dost dlouho, ale z jaké příčiny, to ještě nedokážu říct, nebo, jako Stendhal, předvídat. (Barnes, Julian (2009): Žádný důvod k obavám. Překlad: Fantys, Petr. Praha: Odeon.)

Das nächste derbe, zur rein semantischen Äquivalenz gehörende Phraseolexem lautet im Deutschen `kein Arsch`, im Tschechischen rani nohar (wörtl.: nicht einmal ein Bein) und bedeutet >niemand.${ }^{35}$ Während das Phrasem im Deutschen als umgangssprachlich bis derb betrachtet wird, ist die Entsprechung im Tschechischen scherzhaft. Im DeReKo findet man zum 20.10.2017 insgesamt 65 Treffer zu dem Phraseologismus. Nach manuellem Durchgehen bleiben allerding lediglich 28 Treffer für die oben angegebene Bedeutung. Im TscheKo sind es 106 Belege.

Meine Frau Claudia und der Journalist Alex Raack haben das Projekt angestoßen. Es war der richtige Zeitpunkt, diese Geschichte jetzt zu erzählen. Im Jahr 2000 (direkt nach der Therapie, Anm. d. Red.) hätte ich das noch nicht gekonnt, in 15 Jahren wäre es zu spät, da kennt mich kein Arsch mehr. (NUZ13/FEB.01108 Nürnberger Zeitung, 14.02.2013, S. 3; Uli Borowka zu Gast in Nürnberg - Doppelleben als Fußballer und Trinker)

Rozhled na Atény, v nichž žije více než třetina Řeků, je nádherný: moře, Akropolis, bílé město usazené ve zvlněné krajině. Nikde ani noha. Vyrazila jsem pozdě odpoledne $s$ nadějí, že výheň už bude ustupovat. Neustupuje. Jak může být produktivita této země srovnatelná s Německem? A proč by vlastně měla být? Ve vedru nemůže člověk vydávat prŕliš energie. (Lidové noviny, 17.7.2010)

Das derbe Phraseolexem `für den Arsch sein` im Deutschen findet sein Pendant im Tschechischen in >být na hovno ${ }^{36}$ (wörtl.: für die Scheiße sein). Beide Phraseologismen haben die gleiche Bedeutung, nämlich >sinnlos, nutzlos, wertlos, vergeblich sein $r .{ }^{37}$ Das DeReKo bringt zum 20.10.2017 insgesamt 80 Treffer, die meisten in diesem Sinne und zwar überwiegend in Texten über Ereignisse im Bereich des Sports. Im TscheKo sind es 141 Belege.

Redensartenindex, Stichwort: »kein Arsch«.

Weitere Varianten im Tschechischen sind nach Heřman et al. (Deutsch-tschechisches Wörterbuch, S. 103): ‘být na nic, na houby, na draka, k ničemu, na prd` (wörtl.: für nichts / für die Pilze / für den Drachen / zu nichts / für den Furz sein).

37 Redensartenindex, Stichwort: »für den Arsch sein«. 


\begin{abstract}
Vor allem die ersten 20 Minuten in der neuen europäischen »Königsklasse« boten Trainer Benoit Laporte reichlich Vorführmaterial für Analysen während der Vorbereitung. Unnötige Strafen und nicht ausreichendes Abwehrverhalten führten zu einem deftigen 0:4-Rückstand, dem die Freezers fortan hinterherliefen. Kapitän Christoph Schubert fasste passend zusammen: »Die ersten 20 Minuten waren für den Arsch. «Dass das keine Schande ist, zeigt ein Blick auf den Gegner. Lulea gehört zu den Topteams in Schweden und ganz Europa. Die Skandinavier sind zudem schon vier Wochen länger in der Vorbereitung. (HMP14/AUG.01688 Hamburger Morgenpost, 23.08.2014, S. 42; 1:4! Fehlstart in die Königsklasse)
\end{abstract}

Slova Havlovy hry se ve zvukovém plánu inscenace »zdrcla« do zacyklených smyček vytvořených z původní nahrávky Audience. Nutkavé refrény »napijeme se«, »lidi jsou svině«, "všechno je na hovno" se nakonec spojí prímo v esenci pivní filozofie. Vesmírné šumění je podvakrát přehlušeno jásavým tenorem Karla Gotta. Včelku Máju Sládek využije k brilantní estrádní kreaci a píseň Když jsem já byl tenkrát kluk spojí pijáky piva v objetí. (Hospodářské noviny, 25.7.2013)

\title{
4. Typ der nichtphraseologischen Äquivalenz: Nulläquivalenz
}

Unter Nulläquivalenz versteht Henschel Phraseme, die in der anderen Sprache »nicht mit adäquaten, d.h. phraseologischen, Mitteln wiedergegeben werden [können] «. ${ }^{38}$ Dafür stehen nur nichtphraseologische Mittel zur Verfügung. Nach Henschel ${ }^{39}$ zählen »expressive Einwortlexeme«, »nichtexpressive Einwortlexeme und freie Wortverbindungen «, »Periphrasen « und »die Angabe der wörtlichen Bedeutung « dazu. In unserem Korpus gibt es 30 deutsche Phraseologismen, für die keine phraseologischen Entsprechungen im Tschechischen gefunden werden konnte.

$\mathrm{Zu}$ dieser Gruppe gehört beispielsweise die derbe phraseologische Wortverbindung >Arsch mit Ohren « im Sinne von `Schimpfwort für jmdn., der einem durch sein Verhalten oder Aussehen widerlich ist $\triangleleft .{ }^{40} \mathrm{Im}$ Tschechischen kann dieses Phraseolexem mit expressiven Einwortlexemen ausgedrückt werden und zwar >pitomec`, >blbec`, >vůl (wörtl.: Dummkopf, Blödmann, Ochse). Das DeReKo bringt zum 22.10.2017 insgesamt 121 Treffer. Nicht alle Belegstellen handeln tatsächlich von dieser Redewendung in der genannten Bedeutung. Mehrmals geht es um die Bezeichnung für eine Auszeichnung für Humoristen oder Kabarettisten, die >Arsch mit Ohren` heißt.

Den ersten Platz erreichte Klaus Neufeld mit einem 58,5 Teiler. Auf den zweiten Platz kam Hans Fritzsch mit einem 62,7 Teiler, den dritten Platz belegte Marion Rieger mit einem

39 Ebd., S. 143.

40 Duden 11 (2002), S. 60. 
79,6 Teiler. Der letzte Platz sollte nicht leer ausgehen, denn mit einem 355,5 Teiler bekam Julia Rieger den in Bronze gegossenen "Arsch mit Ohren « überreicht. (BRZ13/JAN.02685 Braunschweiger Zeitung, 09.01.2013, Lokalteil: Peiner Nachrichten. - Sachgebiet: Lokales, Originalressort: Peine-Lokal; Neujahrspokalschießen in Ilsede)

Das nächste derbe Beispiel für diese Gruppe ist ıjmdn. am Arsch kriegen im Sinne von $>$ jmdn. ergreifen/erwischen/bestrafen $\triangleleft{ }^{41} \mathrm{Im}$ Tschechischen wird dieser Phraseologismus mit nichtexpressiven Einwortlexemen wiedergegeben und zwar `někoho dostat, chytit, chytnout, drapnout, dopadnout ${ }^{42}$ (wörtl.: jmdn. erwischen, fangen, packen, schnappen). Im DeReKo findet man zum 22.10.2017 insgesamt 3 Treffer zu der Nennform.

Von seinem Versteck beobachtete Schmökel das Kind, und plötzlich konnte er nichts anderes mehr denken. „Ich wollte das Mädchen schlagen, dass es wimmert, ich wollte es missbrauchen.” Und die Gelegenheit schien günstig. Schmökel stand ohnehin schon mit dem Rücken zur Wand. „Wenn die mich eh am Arsch kriegen, dann kannst du auch noch schnell ein Mädchen missbrauchen", habe er sich damals gedacht. Schmökel sagt das, als trauere er der verpassten Chance bis heute nach. (U02/NOV.01716 Süddeutsche Zeitung, 12.11.2002, S. 9. Originalressort: Themen aus Deutschland; Schmökels erste Aussage vor dem Landgericht Neuruppin)

Den Phraseologismus > wie Arsch und Friedrich schlecht ${ }^{43}$ kann man im Tschechischen nicht phraseologisch, sondern ausschließlich sinngemäß wiedergeben, nämlich `velmi špatně`. Das DeReKo liefert zum 26.10.2017 insgesamt 13 Treffer zu diesem Phraseolexem. Die meisten Belege, insgesamt sechs, sind mit dem Verb sklingen` verbunden, weitere Verben, die jeweils zweimal verwendet wurden, sind saussehen und sschmecken .

Ihre Leidenschaft fürs Nähen entdeckte sie als Teenager, als sie die New-Wave-Klamotten, die sie tragen wollte, in keinem Laden fand oder die schlicht zu teuer waren. Später kam noch der Frust darüber hinzu, dass »Kleider von der Stange an vielen Frauen aussehen wie Arsch und Friedrich«. (FOC09/MAI.00507 FOCUS, 30.05.2009, S. 80-81, Sachgebiet: Mode, Originalressort: Modernes Leben; Selig mit der neuesten Masche)

\section{Phraseologische $>$ faux amis}

Die phraseologischen `faux amis`, von Henschel `falsche Freunde werden als »formal identische oder fast identische Einheiten zweier Sprachen [bezeichnet], deren Bedeutungen aber nichts miteinander zu tun ha- 
ben. Das übereinstimmende innere Bild wird verschieden gedeutet $[\ldots] \ll{ }^{44}$ In unserem Korpus wurden fünf phraseologische Paare gefunden, die diesen Bedingungen entsprechen. Es handelt sich im Deutschen u.a. um jjmdn. am/ beim Arsch haben $<$ im Sinne von >jmdn. für etwas verantwortlich machen $\triangleleft{ }^{45}$ und im Tschechischen >mít někoho/něco u prdele` (wörtl.: jmdn./etw. am/ beim Arsch haben) in der Bedeutung >jmd./etw. ist mir egal; jmd./etw. interessiert mich nicht . Im TscheKo wurden zum 26.10.2017 insgesamt vier Belege für den Phraseologismus gefunden, einer davon mit einer Person verbunden, die anderen drei waren sachlich.

»Je mi líto, když musím říct, že i ti blbý komunisti nebyli takový hovada, jako tam jsou dnes. At' se komančové klidně vrátěj zpět, protože to už tady nebudu. At' tuhle díru zavezou hnojem, mám to u prdele, « pokračoval zhurta tatér. Češi vůdcům EU nevěří. Polovina obyvatel Evropské unie je přesvědčena, že lídři Evropské unie se dovedou postavit globálním výzvám, 42 \% jich tomu nevěŕí. (Parlamentní listy, č. 6/2012)

»Je jiná doba - žádná vláda, ani liberální, ani labouristická, se o vzdělání nestará ani hovno. Jsou tam drogy a nemají dost učitelů. « »Drogy jsou všude.« Harry se odvrátil od Garyho a zašeptal Manolisovi řecky: »Australani mají svoje děti u prdele. « Hectorův otec se zasmál, ale náhle promluvila maminka. »Ale co když všichni svoje děti pošlou do soukromých škol? To bude špatné pro státní školy. Pak tam budou chodit jenom hodně chudí a vláda žádné další peníze na vzdělání nedá.« (Tsiolkas, Christos (2011): Facka. Překlad: Kačer, Tomáš. Brno: Host.)

Im DeReKo konnten zum 26.10.2017 keine Treffer zu dem deutschen Phraseolexem festgestellt werden.

\section{Ergebnisse der Untersuchung}

In dem vorliegenden Beitrag wurden insgesamt 111 Phraseologismen im Deutschen mit der Komponente >Arsch ‘ mit ihren Pendants im Tschechischen verglichen. Der Analyse liegt die Klassifizierung von Henschel (1993) zugrunde. Als Ergebnis der kontrastiven Untersuchung der Phraseologismen mit der Komponente >Arsch kann festgehalten werden, dass 16 phraseologische Paare (d.h. 14\%) vollständig äquivalent, 17 (d.h. 15\%) partiell äquivalent sind. Die rein semantische Äquivalenz weisen 43 phraseologische Paare (d.h. 39\%) auf. Die Nulläquivalenz liegt bei 30 deutschen Phraseologismen (d.h. 27\%) vor, d.h. dass zu diesen Phraseologismen im Deutschen keine phraseologischen Entsprechungen im Tschechischen gefunden werden konnten und dass sie schließlich mit nichtphraseologischen 
Mitteln ins Tschechische übertragen werden mussten. Fünf phraseologische Paare (d.h. 5\%) im Deutschen und im Tschechischen zählen zu den phraseologischen faux amisr.

Die Annahme, dass die derben und vulgären Ausdrücke mit der Komponente $>$ Arsch nur zum gesprochenen Sprachschatz gehören, wurde teilweise widerlegt, denn in dem DeReKo finden sich zu vielen dieser Phraseologismen eine ganze Reihe von Belegen aus Presseartikeln. In der Regel machen die Autoren jedoch deutlich, dass sie damit die Stilebene der Standardsprache verlassen und zur derben Stilebene wechseln. So kommen diese Ausdrücke häufig in der direkten Rede vor, also als Zitat eines anderen Sprechers. Oder man signalisiert den Stilwechsel durch Interpunktion, nämlich mit der Verwendung von Anführungszeichen. Eine weitere Möglichkeit, sich von dieser derben Ausdrucksweise zu distanzieren, ist der Einschub von Füllwörtern wie `wie man so sagt`, >sozusagen ` oder `auf gut Deutsch ‘. In dem TscheKo wurden die Belege hauptsächlich der Belletristik entnommen. Hier handelt es sich allerdings oft um direkte Rede, Dialoge oder Formulierungen des Ich-Erzählers.

\section{Literaturverzeichnis}

Burger, Harald: Phraseologie. Eine Einführung am Beispiel des Deutschen. Berlin: Erich Schmidt Verlag 2007.

Čermák, František; Hronek, Jiř́; Machač, Jaroslav et al.: Slovník české frazeologie a idiomatiky. Výrazy slovesné. Band 3. Praha 2009.

Deutsches Referenzkorpus (DeReKo-2017-I) / alle öffentlichen Korpora des Archivs W (mit Neuakquisitionen). COSMAS II-Server, C2API-Version 4.10.5-26.7.2017. Mannheim: Institut für Deutsche Sprache. <http://www.ids-mannheim.de/DeReKo> (Zugriff: 27.10.2017).

Duden 11. Redewendungen und sprichwörtliche Redensarten. Idiomatisches Wörterbuch der deutschen Sprache. Günther Drosdowski. Mannheim: Dudenverlag 1992.

Duden 11. Redewendungen. Wörterbuch der deutschen Idiomatik. Brigitte Alsleben, Werner Scholze-Stubenrecht. 2., neu bearb. u. aktualis. Aufl. Mannheim: Bibliographisches Institut und F. A. Brockhaus 2002.

Duden online. Berlin: Bibliographisches Institut, Dudenverlag <https://www.duden.de> (Zugriff: 27.10.2017).

Fleischer, Wolfgang: Phraseologie der deutschen Gegenwartssprache. 2. Aufl. Tübingen: Max Niemeyer Verlag 1997.

Goethe, Johann Wolfgang von: Werke. Jubiläumsausgabe. Zweiter Band. Frankfurt/M. und Leipzig: Insel Verlag 1998.

Goethe, Johann Wolfgang von: Götz von Berlichingen mit der eisernen Hand. Ein Schauspiel. Stuttgart: Reclam 1969.

Goethe, Johann Wolfgang von: Götz von Berlichingen mit der eisernen Hand. Ein Schauspiel. Hamburg: Hamburger Lesehefte (o. J.). 
Henschel, Helgunde: Die Phraseologie der tschechischen Sprache. Ein Handbuch. Frankfurt/M.: Peter Lang 1993.

Heřman, Karel; Blažejová, Markéta; Goldhahn, Helge et al.: Deutsch-tschechisches Wörterbuch der Phraseologismen und festgeprägten Wendungen. 1. Aufl. Praha: C. H. Beck 2010.

Hofmannová, Jana: Numeralien als phraseologische Komponenten im Deutschen und im Tschechischen am Beispiel des Numerales VIER. In:»Brünner Beiträge zur Germanistik und Nordistik «29/1, Masarykova univerzita 2015, S. 47-67.

Hofmannová, Jana: Numeralien als phraseologische Komponenten im Deutschen und im Tschechischen am Beispiel des Numerales SIEBEN. In: »Lingua viva «20, České Budějovice 2015, S. 37-49.

Redensartenindex. Wörterbuch für Redensarten, Redewendungen, idiomatische Ausdrücke, Sprichwörter, Umgangssprache [ohne Impressum]. <https://www.redensarten-index. de/suche.php> (Zugriff: 27.10.2017).

SYN2015: reprezentativní korpus psané češtiny. Praha: Ústav Českého národního korpusu FF UK 2015. <http://www.korpus.cz> (Zugriff: 27.10.2017).

Röhrich, Lutz: Lexikon der sprichwörtlichen Redensarten. 4. Aufl. Freiburg, Basel, Wien 1994. Wiktionary. Das freie Wörterbuch. <https://de.wiktionary.org> (Zugriff: 27. 10. 2017). 